\title{
Frequent loss of the long arm of chromosome 18 in esophageal squamous cell carcinoma
}

\author{
TAKUYA ANDO, HIDEYUKI ISHIGURO, MASAHIRO KIMURA, AKIRA MITSUI, YOICHIRO MORI, \\ NOBUYOSHI SUGITO, KEISUKE TOMODA, RYOTA MORI, KOSHIRO HARADA, \\ TAKEYASU KATADA, RYO OGAWA, YOSHITAKA FUJII and YOSHIYUKI KUWABARA \\ Department of Surgery II, Nagoya City University Medical School, 1 Kawasumi, \\ Mizuho-cho, Mizuho-ku, Nagoya 467-8601, Japan
}

Received October 6, 2006; Accepted January 5, 2007

\begin{abstract}
Esophageal squamous cell carcinoma (ESCC) is one of the most common and deadly cancers in Japan. In this study we performed fluorescent in situ hybridization (FISH) and loss of heterozygosity ( $\mathrm{LOH}$ ) analysis for chromosome $18 \mathrm{q}$ in ESCC cells to investigate allelic imbalance of chromosome $18 \mathrm{q}$ in ESCC. In the FISH analysis, only one signal for chromosome $18 \mathrm{q}$ was detected in TE-1 esophageal cancer cells, whereas two signals were detected in TE- 2 cells. Two of five resected ESCC samples from patients showed loss of one copy of chromosome 18q. To construct a precise deletion map of chromosome 18q, LOH analysis was performed using 30 microsatellite markers localized to chromosome 18q. LOH was observed in 31 of 46 ESCC samples $(67.4 \%)$ for at least one locus on chromosome 18q. LOH frequency for individual markers varied from $18.5 \%$ (D18S460) to $48.4 \%$ (D18S866). Thirteen of 46 ESCC samples (28.3\%) showed the loss of most of the long arm of chromosome 18. Lymph node metastasis and vein invasion were significantly associated with the deletion of chromosome 18q. Loss of chromosome 18q may play an important role in the progression of ESCC.
\end{abstract}

\section{Introduction}

Esophageal squamous cell carcinoma (ESCC) is the sixth most frequent cancer in Japan, and the number of deaths due to this cancer has been steadily increasing. ESCC is often diagnosed at an advanced stage, and the prognosis for patients with ESCC remains poor, prompting the search for new treatment strategies. Recent molecular biological studies have revealed that esophageal cancer is caused by the accumulation

Correspondence to: Dr Hideyuki Ishiguro, Department of Surgery II, Nagoya City University Medical School, 1 Kawasumi, Mizuho-cho, Mizuho-ku, Nagoya 467-8601, Japan

E-mail: h-ishi@med.nagoya-cu.ac.jp

Key words: 18q, loss of heterozygosity, esophageal squamous cell carcinoma, fluorescent in situ hybridization of multiple genetic abnormalities in dominant oncogenes and tumor suppressor genes.

Molecular cytogenetic alterations associated with ESCC have been identified, including loss of heterozygosity ( $\mathrm{LOH})$, which implies the existence of recessive tumor suppressor genes. Evaluating LOH is useful to assess gene inactivation and for functional evaluation of candidate tumor suppressor genes.

Recent studies using comparative genomic hybridization (CGH) (1-9) have shown that multiple chromosomal regions are lost in ESCC, and losses of chromosomes 3p, 4p, 4q, 5q, $9 p$ and $18 q$ are particularly frequent, suggesting that tumor suppressor genes associated with the tumorigenesis of ESCC may be located on these chromosomes. Among these chromosomal regions, loss of chromosome $18 \mathrm{q}$ is most frequent, and $\mathrm{LOH}$ analysis for chromosome $18 \mathrm{q}$ has been performed in other malignancies such as colon $(10,11)$, pancreatic (12), and ovarian (13) cancer, and head and neck squamous cell carcinoma (HNSCC) (14-16). However, detailed LOH analysis for chromosome 18q in ESCC has not been carried out. We thus focused on chromosome $18 \mathrm{q}$ and performed detailed $\mathrm{LOH}$ analysis for this region in order to examine the association between deletion of chromosome 18q and ESCC tumorigenesis.

In this study, we first used fluorescent in situ hybridization (FISH) analysis for esophageal cancer cell lines and resected ESCC samples, and then LOH analysis was performed to construct a detailed deletion map in order to define the precise region of chromosome $18 \mathrm{q}$ that is deleted in ESCC.

\section{Materials and methods}

Cell lines and tissue samples. The esophageal cancer cell lines TE- 1 and TE-2 were purchased from the Japanese Cancer Research Resources Bank. The esophageal cancer cells were plated in tissue culture dishes and grown in RPMI-1640 medium (Sigma, St. Louis, MO, USA) with $10 \%$ fetal bovine serum (JRH Bioscience, Lenexa, KS, USA) at $37^{\circ} \mathrm{C}$ in a humidified atmosphere of $95 \%$ air and $5 \% \mathrm{CO}_{2}$.

Samples were obtained from 46 patients with primary ESCC who had undergone radical esophagectomy at the Department of Surgery II, Nagoya City University Medical School, between 1996 and 2001. The study design was 

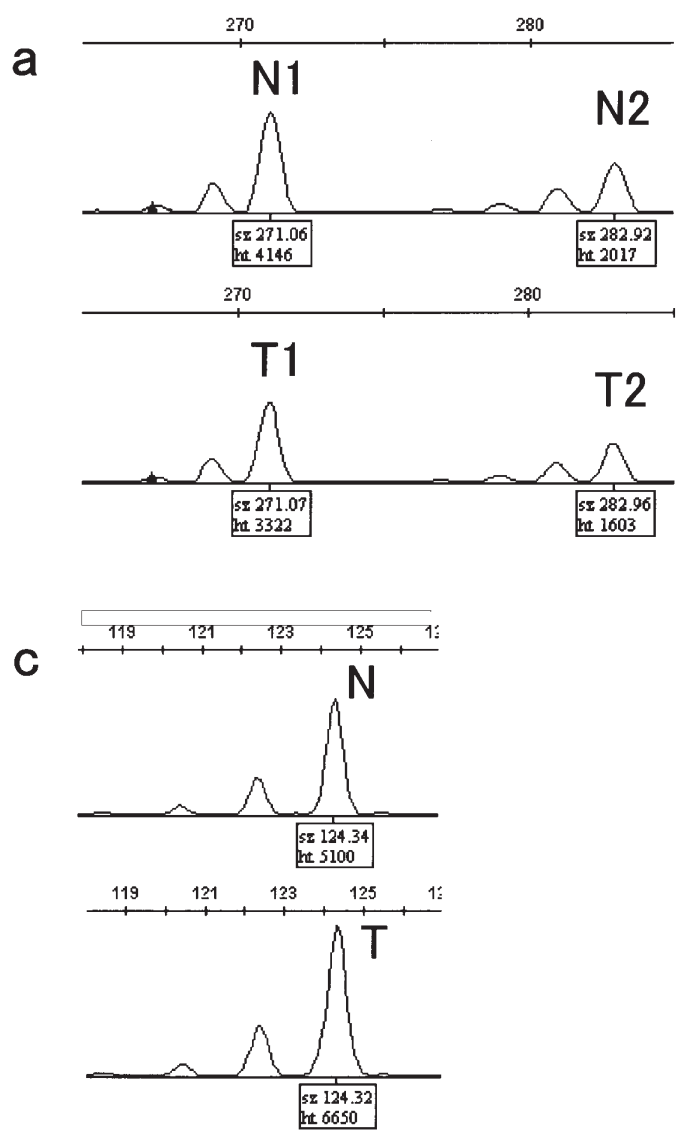

Figure 1. Representative examples of $\mathrm{LOH}$ assessment. (a) Case with no LOH for the D18S1144 marker (case 01-14). (b) Case with LOH for the D18S56 marker (case 00-5). (c) Case that was not informative with respect to D18S866 (case 00-7).

approved by the Institutional Research Board of our university and written consent was obtained from all of the patients. Tumors were classified according to the Japanese guidelines for clinical and pathological studies on carcinoma of the esophagus. Samples were taken from 35 males and 11 females,

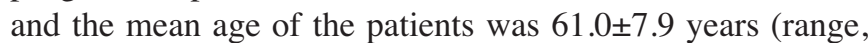
47-79 years). All the samples were frozen immediately in liquid nitrogen and stored at $-80^{\circ} \mathrm{C}$ until use.

FISH analysis. FISH was carried out using the D14Q32/ D18Q21 Dual Color, Dual Fusion Translocation Probe (Vysis, Downer's Grove, IL, USA). The Spectrum Orange-labeled D18Q21 probe spans $7.5 \mathrm{~kb}$, including the entire BCL2 gene. For cell lines, cells were suspended and centrifuged at $1200 \mathrm{rpm}$ for $5 \mathrm{~min}$, and then washed with phosphate-buffered saline. Drops of suspensions were placed on slides and fixed. For ESCC tissue samples, $5-\mu \mathrm{m}$ thick paraffin sections were used. Slides were prepared with $2 \mathrm{X} \mathrm{SSC}(300 \mathrm{mmol} / 1$ sodium chloride, $30 \mathrm{mmol} / 1$ sodium citrate) for $60 \mathrm{~min}$ at $37^{\circ} \mathrm{C}$, and dehydrated for 5 min each with cold 70,90 and $100 \%$ ethanol, and then air dried. Thereafter, slides were treated with proteinase $\mathrm{K}(0.1 \mu \mathrm{g} / \mathrm{ml}$ in $20 \mathrm{mM}$ Tris- $\mathrm{HCl} / 2 \mathrm{mM}$ calcium chloride, $\mathrm{pH}$ 7.0) for $10 \mathrm{~min}$ at room temperature, washed in 2X SSC, then dehydrated and dried. Probes were denatured for $10 \mathrm{~min}$ at $80^{\circ} \mathrm{C}$, prehybridized for $15-30 \mathrm{~min}$ at $37^{\circ} \mathrm{C}$ and

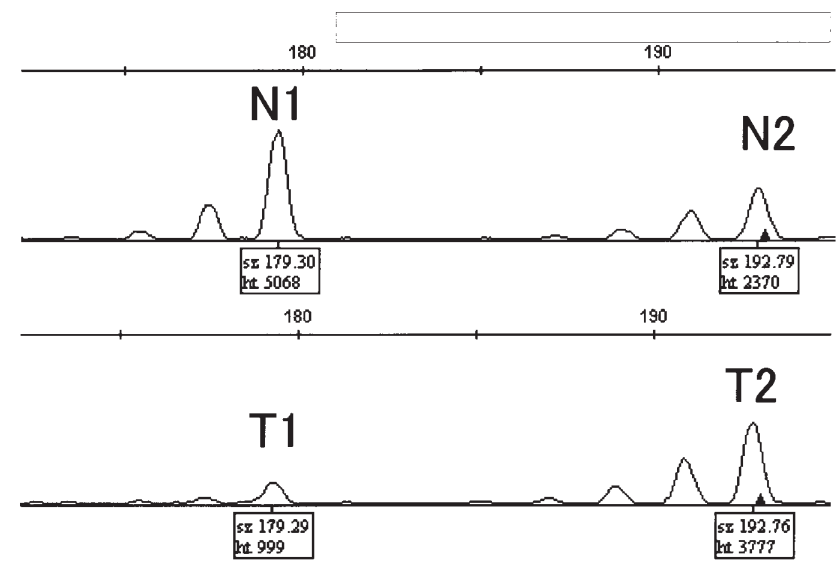

applied to slides at room temperature. Hybridization was carried out overnight at $37^{\circ} \mathrm{C}$. After hybridization, the slides were washed three times for 10 min each in $50 \%$ formamide/ 2X SSC at $45^{\circ} \mathrm{C}$ and then three times for 10 min each in $2 \mathrm{X}$ $\mathrm{SSC}$ at $60^{\circ} \mathrm{C}$. For detection, we used fluorescein isothiocyanate-conjugated anti-digoxigenin (Boehringer Mannheim, Indianapolis, IN, USA), avidin-conjugated Texas Red (Vector Laboratories, Burlingame, CA, USA) or avidin-conjugated CY3 (Amersham Life Science, Little Chalfont, UK). DAPI (4'6-diamidino-2-phenylindole) counterstain was used to visualize interphase nuclei and to identify metaphase chromosomes. Slides were examined using a Leica DMRA2 fluorescence microscope (Leica, Deerfield, IL, USA). Five hundred tumor cells were analyzed for each sample, D14Q32 signals were removed by filter treatment, and numbers of D18Q21 signals were counted as $0,1,2,3$ or 4 , or more signals.

DNA extraction. Snap frozen samples $\left(-80^{\circ} \mathrm{C}\right)$ were obtained for the esophageal cancer tissue and corresponding normal esophageal mucosa taken from apparently non-cancerous mucosa as far away from the tumor as possible. Genomic DNA was extracted by incubating each sample in $100 \mu \mathrm{l}$ of a solution containing $50 \mathrm{mM}$ Tris- $\mathrm{HCl}, 1 \mathrm{mM}$ ethylenediamine tetraacetic acid, $0.5 \%$ (v/v) Tween-20, and $0.5 \mathrm{mg} / \mathrm{ml}$ proteinase $\mathrm{K}$ (pH 8.0) in a shaking incubator at $37^{\circ} \mathrm{C}$ overnight. Samples were then boiled for $10 \mathrm{~min}$ and vortexed. We used this method to obtain DNA from both cancer tissue and normal mucosa. The concentration of the genomic DNA was adjusted to $50 \mathrm{ng} /$ $\mu \mathrm{l}$ by using a spectrophotometer.

Primers and polymerase chain reaction. We chose 30 microsatellite markers at intervals of roughly $2 \mathrm{~cm}$ on the long arm of chromosome 18. Details about the cytogenetic localization and microsatellite sequences of the markers were obtained from the Genome Database (http://www.gdb.org./) and National Center for Biotechnology Information genome database (http://www.ncbi.nlm.nih.gov/). The oligonucleotides were labeled fluorescently with one of three dyes (6-FAM, NED, VIC) at the 5'-end.

The polymerase chain reactions for genotyping were performed using the GeneAmp System 9600 (Perkin-Elmer, Branchburg, NJ, USA). Reactions were carried out in a 

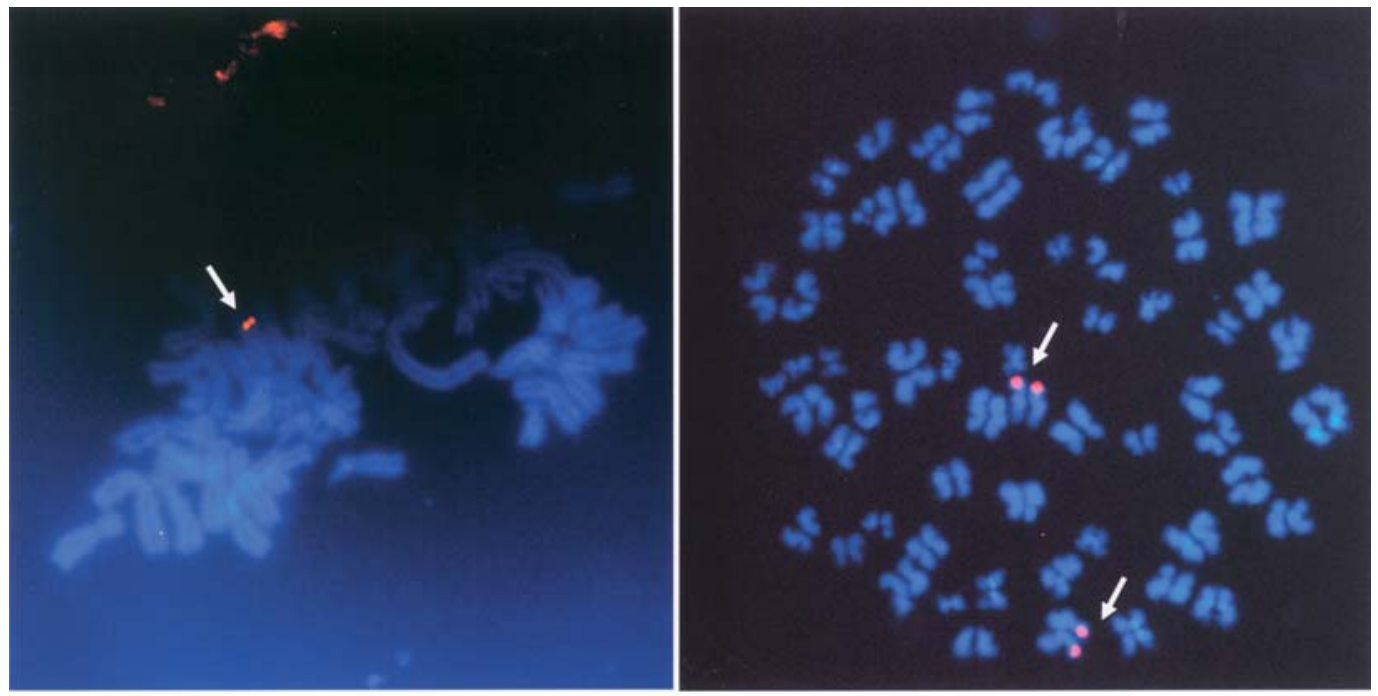

a

b

Figure 2. FISH analysis using the D18Q21 probe in esophageal cancer cell lines in metaphase. (a) Only one D18Q21 signal was detected in TE-1 (represented by two dots on one pair of sister chromatids; arrow). (b) Two signals were detected in TE-2 (arrows).

volume of $15 \mu 1$ containing $9.0 \mu 1$ True Allele PCR Premix (Applied Biosystems, Foster City, CA, USA), $3.8 \mu 1$ sterile deionized water, $60 \mathrm{ng}$ DNA, and 5 pmol of each primer. The thermal profile was as follows: initial denaturation at $94^{\circ} \mathrm{C}$ for $12 \mathrm{~min}$ followed by 10 cycles of denaturation at $94^{\circ} \mathrm{C}$ for $15 \mathrm{sec}$, annealing at $55^{\circ} \mathrm{C}$ for $15 \mathrm{sec}$, extension at $72^{\circ} \mathrm{C}$ for $30 \mathrm{sec}$ and then 20 cycles of denaturation at $89^{\circ} \mathrm{C}$ for $15 \mathrm{sec}$, annealing at $55^{\circ} \mathrm{C}$ for $15 \mathrm{sec}$, extension at $72^{\circ} \mathrm{C}$ for $30 \mathrm{sec}$ and final extension at $72^{\circ} \mathrm{C}$ for $10 \mathrm{~min}$.

Electrophoresis. Electrophoresis was performed using an ABI PRISM 310 genetic analyzer. The PCR products were pooled in eight groups, each consisting of $20 \mu \mathrm{l}$. One microliter of this mixture was added to $12 \mu \mathrm{l}$ of Hi-Di Formamide (Applied Biosystems) and $0.5 \mu 1$ of 500 LIZ Size Standard (Applied Biosystems) and then denatured at $95^{\circ} \mathrm{C}$ for $2 \mathrm{~min}$ before electrophoresis.

LOH analysis. The data were analyzed with Gene Mapper version 3.0 (Applied Biosystems). The peaks of the normal sample were used to determine whether the sample was homozygous (one peak only) or heterozygous (two peaks). Heights of the allele peaks were assigned. The ratio of alleles was calculated for each normal tissue and tumor pair, and the tumor ratio was divided by the normal ratio; that is, T2:T1/ $\mathrm{N} 2$ :N1 (where T1 and N1 are the area values for the shorter alleles, and T2 and N2 are the values for the longer alleles, where $\mathrm{T}$ stands for tumor and $\mathrm{N}$ stands for normal). $\mathrm{LOH}$ was defined as a ratio of $<0.75$ or $>1.33$, representing an allelic signal reduction of at least $25 \%$ (Fig. 1).

Statistical analysis. Statistical analysis was carried out using the Stat-View software package (Abacus Concepts, Berkeley, CA, USA). The $\chi^{2}$ test and Fisher's exact test were used to analyze the association between $\mathrm{LOH}$ and the clinical histopathological parameters of patients.
The survival of ESCC patients after surgery was examined by the Kaplan-Meier method, and survival time was compared using the log-rank test. In all analyses, $\mathrm{P}<0.05$ was considered statistically significant.

\section{Results}

FISH analysis. We first performed FISH analysis, in order to confirm the loss of chromosome 18q in ESCC cell lines and resected ESCC specimens. FISH analysis for two esophageal cancer cell lines (TE-1 and TE-2) was performed using the D18Q21 probe. Both cell lines seemed to be aneuploid. In the metaphase of TE-1 cells, only one D18Q21 signal was detected (represented by two dots on one pair of sister chromatids) (Fig. 2a). Two signals were detected in TE-2 (Fig. 2b). These findings suggest that TE-1 cells have lost one copy of chromosome 18 or a large part of chromosome 18 including D18Q21.

We next performed FISH analysis using five resected ESCC specimens. Representative results for case 98-15 (Fig. 3a) and case 01-9 (Fig. 3b) are shown. Five hundred tumor cells were counted for each sample, and the result is summarized in Table I. Most cells were diploid in terms of D18Q21. Of the five specimens, two specimens (cases 98-7 and 98-15) contained $>10 \%$ of cells that included only one D18Q21 signal. This suggests that the D18Q21 signal on one copy of chromosome $18 \mathrm{q}$ was deleted in these cells. Cells that had two D18Q21 signals may have been contaminating non-cancerous stroma cells or the tumor itself may have been heterogeneous.

LOH analysis. To more precisely map the deletion of chromosome 18q, we performed allelic analysis of 46 ESCC specimens using 30 microsatellite markers spanning most of chromosome 18q. In informative cases, $\mathrm{LOH}$ was indicated by significant decreases in the signals of one of the alleles (Fig. 1). A summary of deletion mapping and the locations of 

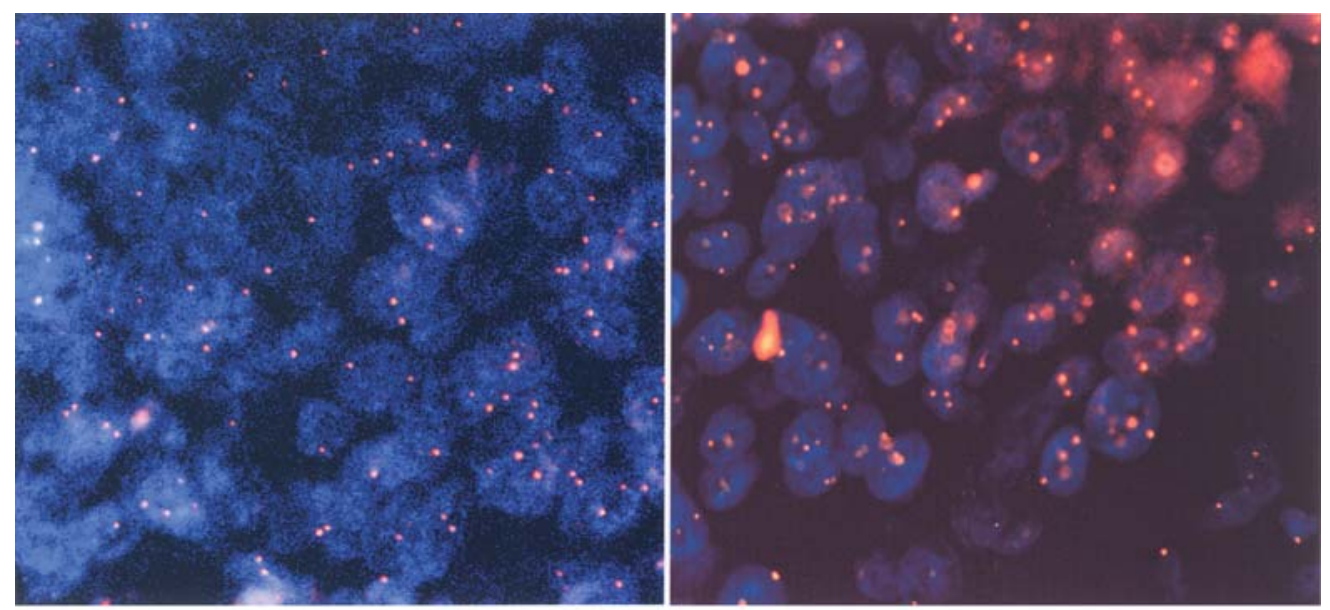

a

b

Figure 3. FISH analysis using the D18Q21 probe in resected ESCC samples. (a) Thirty percent of cells in case 98-15 showed only one D18Q21 signal. (b) Less than $2 \%$ of cells in case $01-9$ showed only one D18Q21 signal.

Table I. FISH analysis of the resected ESCC specimens using D18Q21 probe.

\begin{tabular}{lrrrrr}
\hline Sample ID & $\begin{array}{r}98-6 \\
(\%)\end{array}$ & $\begin{array}{r}98-7 \\
(\%)\end{array}$ & $\begin{array}{c}98-15 \\
(\%)\end{array}$ & $\begin{array}{r}01-3 \\
(\%)\end{array}$ & $\begin{array}{r}01-9 \\
(\%)\end{array}$ \\
\hline 1 signal & 0.0 & 14.0 & 30.0 & 2.2 & 1.2 \\
2 signals & 98.6 & 85.6 & 59.6 & 72.0 & 83.2 \\
3 signals & 1.0 & 0.4 & 5.0 & 14.2 & 3.8 \\
4 signals & 0.2 & 0.0 & 5.4 & 11.6 & 10.2 \\
$>$ 5 signals & 0.2 & 0.0 & 0.0 & 0.0 & 1.6 \\
\hline
\end{tabular}

the 30 markers used in this study are shown in Fig. 4. The samples were informative on average at 19 loci (range 14-23). LOH was observed in 31 of 46 ESCC samples (67.4\%) for at least one locus on chromosome 18q. No replication errors were seen. LOH frequency for individual markers on chromosome $18 \mathrm{q}$ varied from $18.5 \%$ (D18S460) to $48.4 \%$ (D18S866). Six (shown on the far left of Fig. 4) of 46 samples (13.0\%) showed $\mathrm{LOH}$ at all informative markers, suggesting complete loss of chromosome 18q. Seven other samples (including cases 98-7, 99-3, 98-1, 00-8, 98-15, 97-4 and 98-8) showed $\mathrm{LOH}$ at most of the informative markers, but LOH was not detected for a few markers that were located within the region

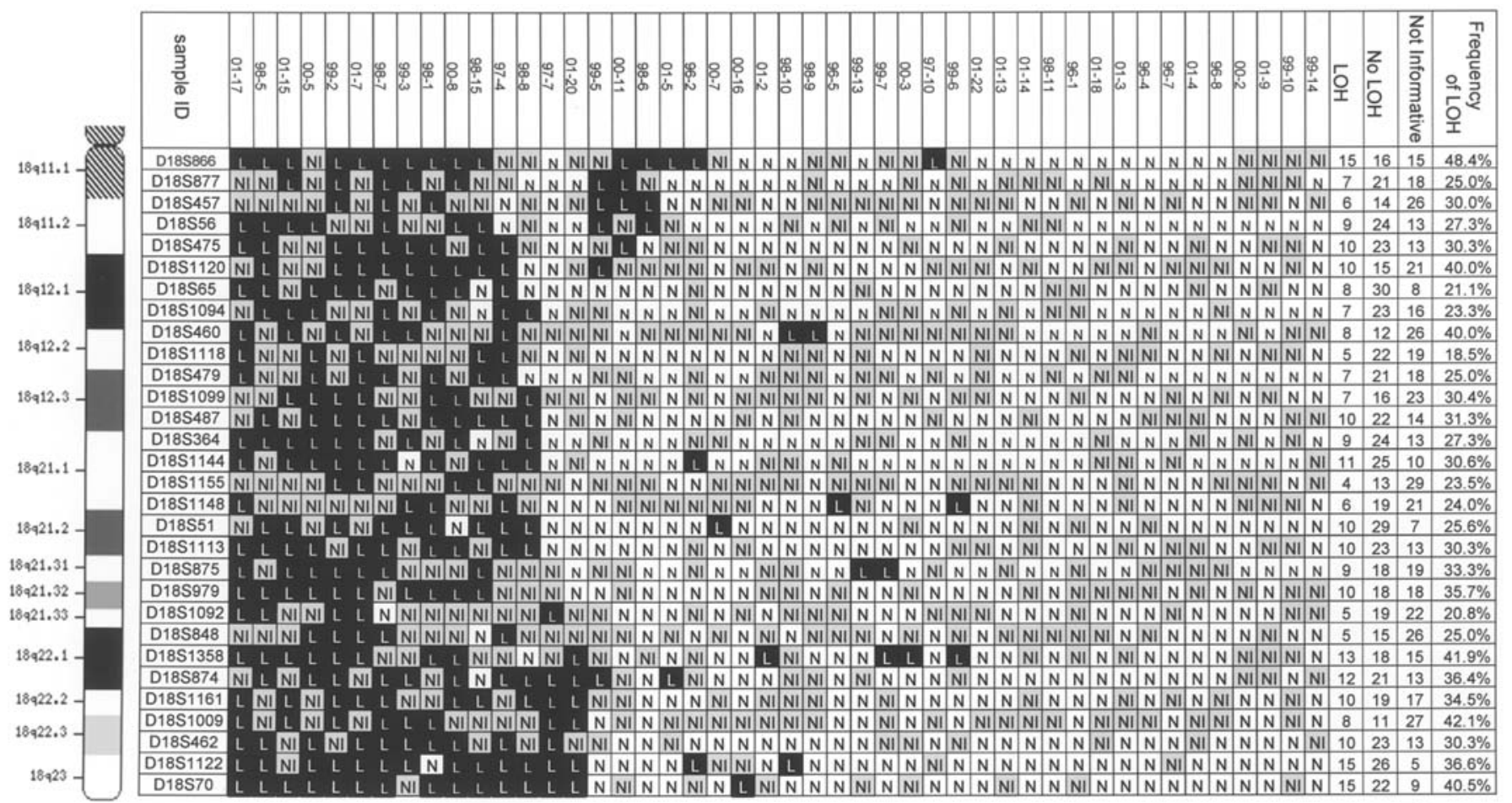

Figure 4. Detailed LOH map for chromosome 18q. Black box with L, LOH; gray box with NI, not informative; white box with N, no LOH. 
Table II. Relationship between LOH and clinicopathological parameters.

Total Deletion No deletion P-value

\begin{tabular}{lrrrr}
\hline $\begin{array}{l}\text { No. of patients } \\
\text { Gender }\end{array}$ & 46 & 13 & 33 & \\
$\quad$ Male & 35 & 9 & 26 & \\
$\quad$ Female & 11 & 4 & 7 & 0.7024 \\
Age at surgery & & & & \\
$\quad<65$ & 32 & 10 & 22 & \\
$>65$ & 14 & 3 & 11 & 0.7241
\end{tabular}

Tumor factor

$\mathrm{T} 1$

$\mathrm{T} 2$

$\begin{array}{rrr}9 & 2 & 7 \\ 6 & 2 & 4 \\ 24 & 8 & 16 \\ 7 & 1 & 6\end{array}$

T4

Lymph node status

$\begin{array}{lrrrr}\text { Negative } & 9 & 0 & 9 & \\ \text { Positive } & 37 & 13 & 24 & 0.0444\end{array}$

Pathological stage

$\begin{array}{lrrrr}0 & 3 & 0 & 3 & \\ \text { I } & 3 & 1 & 2 & \\ \text { II } & 8 & 1 & 7 & \\ \text { III } & 21 & 8 & 13 & \\ \text { IV } & 13 & 3 & 10 & 0.5932\end{array}$

Lymphatic invasion

Negative
Positive
Unknown

$\begin{array}{rrrr}11 & 1 & 10 & \\ 28 & 11 & 17 & 0.1219 \\ 7 & & & \end{array}$

Vein invasion

$\begin{array}{lrrr}\text { Negative } & 21 & 3 & 18 \\ \text { Positive } & 18 & 9 & 9 \\ \text { Unknown } & 7 & & \end{array}$

Histological

differentiation

$\begin{array}{lrrrr}\text { Well } & 18 & 5 & 13 & \\ \text { Moderately } & 22 & 5 & 17 & \\ \text { Poorly } & 4 & 2 & 2 & 0.5291 \\ \text { Unknown } & 2 & & & \end{array}$

Deletion, complete loss of chromosome 18q. No deletion, anything less than complete loss of chromosome $18 \mathrm{q}$.

of extensive LOH. These findings might imply that these markers represent homozygous deletions. These seven cases had most probably lost most of chromosome 18q. The results suggest that at least 13 samples had lost most of the long arm of chromosome 18, which may imply that 13 of 46 samples (28.3\%) had complete loss of chromosome 18q. In two of

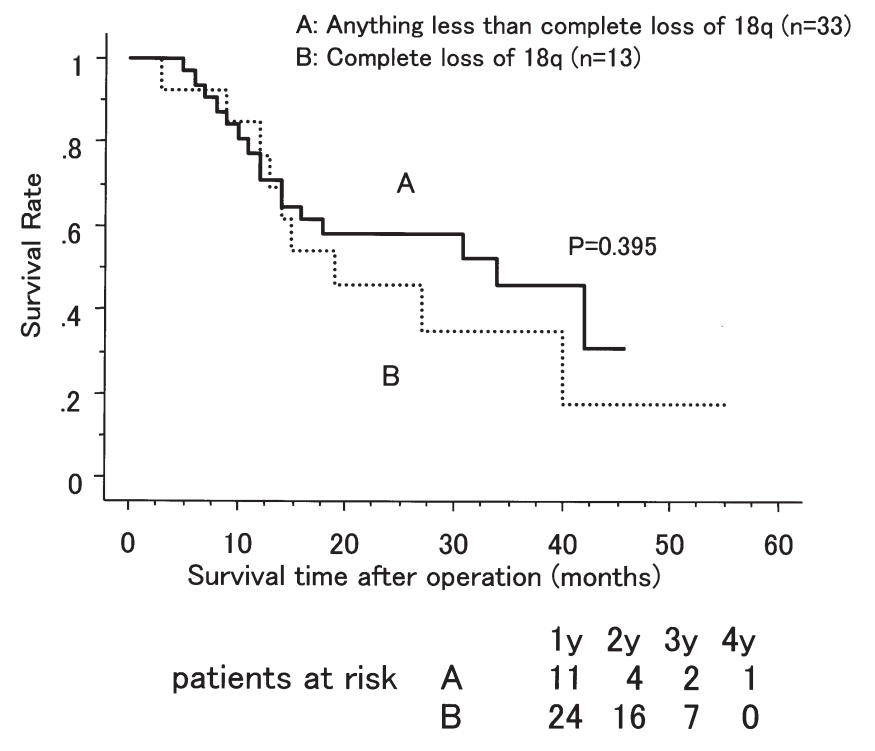

Figure 5. Correlation between complete loss of chromosome $18 \mathrm{q}$ and survival of patients with ESCC. Patients with complete loss of $18 \mathrm{q}$ tended to have shorter survival after surgery compared with patients with anything less than complete loss of $18 \mathrm{q}$; however, the difference was not significant $(\mathrm{P}=0.395$; $\log$-rank test).

these cases (cases 97-4 and 98-8), the loss of 18q may have been incomplete and may have involved only the telomeric side of $18 \mathrm{q}$. Although we did not study the short arm of chromosome 18, it is possible that some samples had lost the entire chromosome. Of the other 33 samples, 15 showed no LOH, three (cases 99-5, 00-11 and 98-6) showed proximal deletion of 18q, and two (cases 97-7 and 01-20) showed partial deletion near the telomere. The other 15 samples showed $\mathrm{LOH}$ at one or two markers; the significance of this finding is unclear (Fig. 4). These results of LOH analysis agreed with the results of FISH analysis. Two samples (cases 98-7 and case 98-15) that showed loss of D18Q21 also showed loss of most of chromosome $18 \mathrm{q}$ in the LOH analysis. The three samples (cases 98-6, 01-3 and 01-9) that showed two D18Q21 signals in FISH analysis also showed retention of both copies of chromosome $18 \mathrm{q}$ in the $\mathrm{LOH}$ analysis.

Relationship between clinicopathological factors and complete loss of $18 q$. We examined the relationship between complete loss of chromosome $18 \mathrm{q}$ and clinicopathological parameters including sex, age, local invasiveness (a tumor factor), lymph node metastasis, pathological stage, lymphatic invasion, vein invasion and histological subtype. Among the parameters analyzed, lymph node metastasis and vein invasion were more commonly observed for 13 tumors with complete loss of $18 \mathrm{q}$ than for the other tumors with anything less than complete loss of chromosome $18 \mathrm{q}$ (Table II). We investigated the correlation between complete loss of chromosome $18 \mathrm{q}$ and survival of patients with ESCC after surgery (median followup, 26.7 months). Patients with complete loss of 18q tended to have shorter survival $(n=13 ; 23.5 \pm 4.0$ months $)$ after surgery compared with patients with anything less than complete loss of $18 \mathrm{q}(\mathrm{n}=33 ; 27.9 \pm 2.8$ months); however, there was no significant difference between these two groups $(\mathrm{P}=0.395$; log-rank test) (Fig. 5). 


\section{Discussion}

Detailed LOH analysis for chromosome 18q has not been reported for ESCC until now. However, LOH on chromosome $18 \mathrm{q}$ is common in several cancers, with frequencies of 55$67 \%$ in colorectal cancer $(10,11), 90 \%$ in pancreatic cancer (12), 59\% in ovarian cancer (13) and $40-84 \%$ in HNSCC (14-16). In those cancers frequent LOH on chromosome $18 \mathrm{q}$ seems to correlate with tumor growth, aggressive tumor behavior and tumorigenesis. These findings suggest that chromosome $18 \mathrm{q}$ may harbor tumor suppressor genes for various cancers. In the present study we found that 31 of 46 ESCC samples (67.4\%) showed allelic loss at one or more markers on chromosome $18 \mathrm{q}$. Thus, chromosome $18 \mathrm{q}$ is very commonly deleted in ESCC as well as in other malignancies.

In the present study we first carried out FISH analysis to confirm the loss of chromosome 18q using the D18Q21 signal. We found that one copy of chromosome $18 \mathrm{q}$ was deleted in one ESCC cell line and some resected ESCC specimens, and we thus hypothesized that deletion around D18Q21 on chromosome $18 \mathrm{q}$ might be a frequent event in ESCC. Therefore we performed allelic analysis of 46 ESCC specimens using 30 microsatellite markers spanning most of chromosome $18 \mathrm{q}$. To our knowledge this is the first detailed $\mathrm{LOH}$ analysis of chromosome 18q in ESCC. This frequency of LOH is similar to that found for chromosome 11, with an $\mathrm{LOH}$ frequency ranging from 13.9 to $58.8 \%$ (17), and also chromosome 13, with an $\mathrm{LOH}$ frequency ranging from 10.4 to $56.7 \%$ (18). For chromosome 9 , a previous study determined an $\mathrm{LOH}$ frequency of between 42.9 and $80 \%$ (19). These findings suggest that chromosomal aberrations occur commonly in ESCC.

The initial aim of this study was to define the precise region of chromosome $18 \mathrm{q}$ that was deleted in ESCC in order to identify candidate tumor suppressor genes. More frequent and extensive loss than expected was detected in chromosome $18 q$, and 13 of 46 samples $(28.3 \%)$ had almost complete loss of chromosome $18 \mathrm{q}$. We also examined the relationship between complete loss of chromosome $18 \mathrm{q}$ and several clinicopathological parameters, and found that complete deletion of chromosome $18 \mathrm{q}$ significantly correlated with lymph node metastasis and vein invasion. Lymph node metastasis and vein invasion were more commonly observed for the 13 tumors with complete loss of chromosome $18 \mathrm{q}$ than for other tumors with anything less than complete loss of chromosome 18q. Complete loss of chromosome 18q could be important for the development and progression of ESCC, including lymph node metastasis and vein invasion, which may imply the existence of recessive tumor suppressor genes on chromosome $18 \mathrm{q}$. This finding also suggests the possibility that lymph node metastasis could be predicted by examining loss of chromosome $18 \mathrm{q}$ in primary ESCC. However, there was no correlation between complete loss of chromosome $18 \mathrm{q}$ and local invasiveness; loss of chromosome 18q may not be necessarily accompanied by an ESCC tumor with severe local invasiveness. In a previous report it was suggested that LOH in esophageal dysplasia is as frequent as it is in superficial and advanced ESCC (20). These findings might suggest that complete loss of chromosome $18 \mathrm{q}$ is not mandatory for the initiation of carcinogenesis or local invasiveness in most cases of ESCC. In the present study, we also assessed the relationship between complete loss of chromosome $18 \mathrm{q}$ and survival. Patients with complete loss of $18 \mathrm{q}$ tended to have poor survival, but the difference was not significant.

Several candidate tumor suppressor genes that map to 18q21, including SMAD2 (21), SMAD4 (12) and DCC (22), have been implicated in other cancers. These genes have already been studied to determine whether they could be tumor suppressor genes in ESCC $(12,22-24)$, but it was found that this is not the case. Therefore, the findings of the present study may imply that other candidate tumor suppressor genes related to ESCC development are present in the long arm of chromosome 18 , but this region is large and so further study will be required to search for and define other candidate tumor suppressor genes.

In conclusion, our study demonstrated that complete loss of chromosome $18 \mathrm{q}$ occurs frequently in ESCC. Moreover, complete loss of chromosome $18 \mathrm{q}$ significantly correlated with lymph node metastasis and vein invasion. Assessment of complete loss of chromosome $18 \mathrm{q}$ might be a useful parameter for predicting which patients lymph node metastasis is likely to occur in. Further studies are needed to restrict the focal region in order to identify which genes are responsible for the development and progression of ESCC.

\section{Acknowledgements}

The authors thank Ms. Shinobu Makino for her excellent technical assistance and Dr Hiromitsu Shimada (Nihon Gene Research Labs, Sendai, Japan) for kind advice regarding FISH.

\section{References}

1. Du Plessis L, Dietzsch E, van Gele M, et al: Mapping of novel regions of DNA gain and loss by comparative genomic hybridization in esophageal carcinoma in the Black and Colored populations of South Africa. Cancer Res 59: 1877-1883, 1999.

2. Pack SD, Karkera JD, Zhuang Z, et al: Molecular cytogenetic fingerprinting of esophageal squamous cell carcinoma by comparative genomic hybridization reveals a consistent pattern of chromosomal alterations. Genes Chromosomes Cancer 25: 160-168, 1999.

3. Pimkhaokham A, Shimada Y, Fukuda Y, et al: Non-random chromosomal imbalances in esophageal squamous cell carcinoma cell lines: possible involvement of the ATF3 and CENPF genes in the 1q32 amplicon. Jpn J Cancer Res 91: 1126-1133, 2000.

4. Mayama T, Fukushige S, Shineha R, Nishihira T, Satomi S and Horii A: Frequent loss of copy number on the long arm of chromosome 21 in human esophageal squamous cell carcinoma. Int J Oncol 17: 245-252, 2000.

5. Tada K, Oka M, Hayashi H, Tangoku A, Oga A and Sasaki K: Cytogenetic analysis of esophageal squamous cell carcinoma cell lines by comparative genomic hybridization: relationship of cytogenetic aberrations to in vitro cell growth. Cancer Genet Cytogenet 117: 108-112, 2000.

6. Yen CC, Chen YJ, Chen JT, et al: Comparative genomic hybridization of esophageal squamous cell carcinoma: correlations between chromosomal aberrations and disease progression/ prognosis. Cancer 92: 2769-2777, 2001.

7. Wei F, Ni J, Wu SS, et al: Cytogenetic studies of esophageal squamous cell carcinomas in the northern Chinese population by comparative genomic hybridization. Cancer Genet Cytogenet 138: 38-43, 2002.

8. Noguchi T, Kimura Y, Takeno S, et al: Chromosomal imbalance in esophageal squamous cell carcinoma: $3 q$ gain correlates with tumor progression but not prognostic significance. Oncol Rep 10: 1393-1400, 2003.

9. Yen CC, Chen YJ, Lu KH, et al: Genotypic analysis of esophageal squamous cell carcinoma by molecular cytogenetics and real-time quantitative polymerase chain reaction. Int $J$ Oncol 23: 871-881, 2003. 
10. Thiagalingam S, Lengauer C, Leach FS, et al: Evaluation of candidate tumour suppressor genes on chromosome 18 in colorectal cancers. Nat Genet 13: 343-346, 1996.

11. Jen J, Kim H, Piantadosi S, et al: Allelic loss of chromosome $18 \mathrm{q}$ and prognosis in colorectal cancer. N Engl J Med 331: 213-221, 1994.

12. Hahn SA, Schutte M, Hoque AT, et al: DPC4, a candidate tumor suppressor gene at human chromosome 18q21.1. Science 271: 350-353, 1996.

13. Lassus H, Salovaara R, Aaltonen LA and Butzow R: Allelic analysis of serous ovarian carcinoma reveals two putative tumor suppressor loci at 18q22-q23 distal to SMAD4, SMAD2 and DCC. Am J Pathol 159: 35-42, 2001.

14. Pearlstein RP, Benninger MS, Carey TE, et al: Loss of $18 \mathrm{q}$ predicts poor survival of patients with squamous cell carcinoma of the head and neck. Genes Chromosomes Cancer 21: 333-339, 1998.

15. Papadimitrakopoulou VA, Oh Y, El-Naggar A, Izzo J, Clayman G and Mao L: Presence of multiple incontiguous deleted regions at the long arm of chromosome 18 in head and neck cancer. Clin Cancer Res 4: 539-544, 1998.

16. Takebayashi S, Ogawa T, Jung KY, et al: Identification of new minimally lost regions on $18 \mathrm{q}$ in head and neck squamous cell carcinoma. Cancer Res 60: 3397-3403, 2000.

17. Lam CT, Tang CM, Lau KW and Lung ML: Loss of heterozygosity on chromosome 11 in esophageal squamous cell carcinomas. Cancer Lett 178: 75-81, 2002.
18. Harada H, Tanaka H, Shimada Y, Shinoda M, Imamura M and Ishizaki $\mathrm{K}$ : Lymph node metastasis is associated with allelic loss on chromosome 13q12-13 in esophageal squamous cell carcinoma. Cancer Res 59: 3724-3729, 1999.

19. Lichun Y, Ching Tang CM, Wai Lau K and Lung ML: Frequent loss of heterozygosity on chromosome 9 in Chinese esophageal squamous cell carcinomas. Cancer Lett 203: 71-77, 2004.

20. Shima H, Hiyama T, Tanaka S, et al: Frequent loss of heterozygosity on chromosome 10p14-p15 in esophageal dysplasia and squamous cell carcinoma. Oncol Rep 12: 333-337, 2004.

21. Eppert K, Scherer SW, Ozcelik H, et al: MADR2 maps to 18q21 and encodes a TGFbeta-regulated MAD-related protein that is functionally mutated in colorectal carcinoma. Cell 86: 543-552, 1996.

22. Fearon ER, Cho KR, Nigro JM, et al: Identification of a chromosome $18 \mathrm{q}$ gene that is altered in colorectal cancers. Science 247 : $49-56,1990$.

23. Maesawa C, Tamura G, Nishizuka S, et al: MAD-related genes on 18q21.1, Smad2 and Smad4, are altered infrequently in esophageal squamous cell carcinoma. Jpn J Cancer Res 88: 340-343, 1997.

24. Maesawa C, Tamura G, Ogasawara S, et al: Loss of heterozygosity at the DCC gene locus is not crucial for the acquisition of metastatic potential in oesophageal squamous cell carcinoma. Eur J Cancer 32A: 896-898, 1996. 